\title{
AS PRÁTICAS PEDAGÓGICAS NORTEADAS PELA INSERÇÃO DA FERRAMENTA TECNOLÓGICA LEGO EDUCATION
}

\author{
Mariza Salete Backes Silva* \\ Alessandra Cristina Furtado**
}

RESUMO: Este artigo tem o objetivo de tratar sobre o uso das tecnologias digitais no processo de ensino e aprendizagem. Para tanto, busca, inicialmente, discorrer acerca da inserção da metodologia LEGO Education na educação escolar e, num segundo momento, analisar a introdução e o seu desenvolvimento nos Anos Iniciais do Ensino Fundamental na Escola SESI, da cidade de Dourados, em Mato Grosso do Sul. Os referenciais que sustentam a abordagem estão ancorados em estudos ligados ao uso das TICs no processo educacional e na formação de professores, bem como, pelo discurso pedagógico sobre os experimentos práticos desta metodologia na vivência docente. Os resultados apontam que o avanço tecnológico promoveu uma evolução significativa no ensino a partir da integração das diferentes mídias digitais para melhorar o ensino-aprendizagem dos alunos e, neste caso, o uso da ferramenta LEGO Education foi utilizada para a ampliação nos espaços de construção do conhecimento do educando. Essa ferramenta se constitui de um programa interdisciplinar tendo a robótica como eixo, utilizada pelas escolas da Rede SESI-MS e também em outros estados brasileiros, tendo a metodologia aplicada nas aulas em concordância com o conteúdo abordado e ministrado no cotidiano escolar, por meio de um ambiente de aprendizagem lúdica, criativa e interativa. A ferramenta tecnológica visa promover o raciocínio lógico, a autonomia e o desenvolvimento de diversas habilidades e competências, especialmente o trabalho em equipe, introduzindo os alunos ao mundo das ciências e das tecnologias, proporcionando-lhes a construção e o aprimoramento dos saberes tecnológicos de forma evolutiva, prática e colaborativa.

\begin{abstract}
This article aims to address the use of digital technologies in the teaching and learning process. To this end, it seeks, initially, to discuss the insertion of the LEGO Education methodology in school education and, in a second moment, to analyze the introduction and its development in the Early Years of Elementary School at the SESI School, in the city of Dourados, in Mato Grosso do South. The references that support the approach are anchored in studies related to the use of ICTs in the educational process and in the training of teachers, as well as by the pedagogical discourse on the practical experiments of this methodology in the teaching experience. The results show that technological advancement has promoted a significant evolution in teaching from the integration of different digital media to improve the teaching-learning of students and, in this case, the use of the LEGO Education tool was used to expand the spaces of construction of the knowledge of the student. This tool consists of an interdisciplinary program with robotics as an axis, used by schools of the SESI-MS Network and also in other Brazilian states, with the methodology applied in classes in accordance with the content addressed and taught in the school routine, through a playful, creative and interactive learning environment. The technological tool aims to promote logical reasoning, autonomy and the development of various skills and competences, especially teamwork, introducing students to the world of science and technology, providing them with the construction and improvement of technological knowledge in a evolutionary, practical and collaborative.
\end{abstract}

PALAVRAS-CHAVE: Educação Tecnológica. Ensino-aprendizagem. Práticas Pedagógicas.

KEYWORDS: Technological Education. Teaching-learning. Pedagogical practices. 


\section{INTRODUÇÃO}

O desenvolvimento acelerado das tecnologias no século XXI, especialmente com a globalização das mídias, levou as sociedades à desenvolverem novas formas no uso das Tecnologias de Informação e Comunicação (TICs) tanto para as pessoas se relacionarem, quanto para ser utilizada na educação direcionada para todas as idades. Neste contexto, as ações envoltas no uso das TICs modificaram a maneira e os conteúdos a serem mobilizados dentro e fora de uma sala de aula, especialmente com a adequação da Robótica Educacional e com a inserção da ferramenta LEGO Education como um componente curricular interdisciplinar em determinadas instituições escolares do país.

O processo tecnológico permeia as transformações nos modos como os indivíduos, se comunicam, trabalham e constroem o conhecimento, este fator consonante ao uso das TICs, abarca mudanças substanciais para toda a sociedade e infere diretamente na educação. No entanto, o uso das tecnologias requer uma reflexão acerca dos próprios conceitos da educação tecnológica, de forma que esteja integrada as propostas pedagógicas que potencializarão o processo do ensino-aprendizagem no educando, de maneira que possa reafirmar o seu lugar na construção do conhecimento e o seu desenvolvimento educacional.

Nesta direção, a Robótica Educacional tem sido um recurso tecnológico utilizado e disseminado em determinadas escolas brasileiras, visando contribuir com o processo de ensino-aprendizagem, ao qual vem crescendo consideravelmente nos últimos anos. Este artigo trata dos usos das ferramentas tecnológicas no processo de ensino e aprendizagem dos Anos Iniciais do Ensino Fundamental, tendo como problemática a seguinte questão: de que maneira o material LEGO Education pode contribuir como ferramenta no processo de ensino-aprendizagem dos alunos nas referidas etapas de escolarização em uma escola do Serviço Social da Indústria (SESI) localizada no município de Dourados, Mato Grosso do Sul?

Os referenciais que sustentaram a abordagem utilizada neste artigo estão ancorados em estudos ligados ao uso da TICs no processo educacional (CARMO, 2013) e na formação de professores (TARDIF, 2011; OLIVEIRA, 2013), bem como no discurso pedagógico sobre os experimentos práticos com o uso da LEGO Education na vivência docente. Para uma aproximação ao objetivo proposto, este artigo foi organizado em duas seções, além desta Introdução e das Considerações Finais. Na primeira seção abordamos os discursos e os saberes pedagógicos inscritos no processo de inserção da metodologia LEGO Education na educação escolar, e, na segunda seção, tratamos sobre o uso das tecnologias pelos professores em sala de aula, a partir de uma experiência com a ferramenta na Escola SESI de Dourados. 
1. OS DISCURSOS PEDAGÓGICOS E A INSERÇÃO DA METODOLOGIA LEGO EDUCATION NA EDUCAÇÃO ESCOLAR

Quando tratamos das ferramentas tecnológicas na educação nos referimos não somente a jogos virtuais ou vídeos explicativos, mas sim, ao uso de uma ferramenta inovadora, como, neste caso, da LEGO Education que possibilita oferecer experiências de aprendizagem inspiradoras que contribuam para o desenvolvimento de habilidades, competências, atitudes e valores no educando por toda a vida. Promovendo também, o aprendizado nas áreas de conhecimento das ciências, do raciocínio lógico matemático e das tecnologias desenvolvidas por meio das montagens, em um ambiente permeado pela ação lúdica e criativa.

É válido destacar que o material LEGOi foi criado pelo dinamarquês e marceneiro de profissão, Ole Kirk Christiansen, em 1934. O LegGodt, como é mundialmente conhecido, significa "brincar bem" e foi construído inicialmente com madeira e, posteriormente com plástico, devido à escassez de matéria-prima. Ele é formado por módulos e blocos de tamanhos e formatos diferentes, que se encaixam, originando diversas combinações e montagens.

O material LEGO Education segue quatro princípios básicos: "alto padrão de qualidade, segurança, estímulo a criatividade e o auxílio no desenvolvimento das crianças, de qualquer faixa etária" (ZOOM, 2020). E, por isso foi integrado ao contexto educacional em diferentes instituições de ensino brasileiras, inclusive na Rede SESI.

Piaget (1974) e Vygotsky (1998), expoentes na educação, com ênfase na infância, apontam as suas teorias de aprendizagem pautadas no construtivismo e no construcionismo, que são as bases epistemológicas do uso e prática da robótica na educação, pois manusear as peças, fazer os encaixes da LEGO Education é uma forma da criança construir seu conhecimento e seu aprendizado. Assim, o aluno é o sujeito da ação que aprende por meio de seus experimentos e da sua interação social, tendo a performance e o protagonismo ao seu alcance, obtendo uma aprendizagem significativa e transformadora. Deste modo, ressaltamos que a criança que utiliza essa ferramenta tecnológica no seu cotidiano escolar, consegue obter melhor desempenho em seu aprendizado.

Mizukami (1986) aponta que as relações entre o cognitivismo, o interacionismo e o construtivismo são intrínsecas, pois são caracterizadas pela capacidade do aluno de se integrar e processá-las, ou seja, o aprendizado além do material didático, relacionado não apenas ao uso dos livros ou registros nos cadernos, mas por meio da inserção da ferramenta LEGO Education, é possível perceber essas ações nos processos centrais da 
aprendizagem do sujeito pautadas na organização do conhecimento, no processamento de informações e nos comportamentos relativos à tomada de decisões.

Este último fator é muito importante, pois define muito a interdependência do aluno com referência ao seu aprendizado e ao professor, pois, ao lidar com situações cotidianas, o educando é movido a resolver problemas reais e significativos, construindo uma aprendizagem de forma prática, lúdica e criativa, e esse é o diferencial apontado ao uso do material LEGO Education nos Anos Iniciais do Ensino Fundamental. Weisz (2018, p.5) destaca que, "Para promover novas aprendizagens, é importante que o professor enxergue o que o aluno já sabe, a partir do que ele produz, reconhecendo suas potencialidades desde o início da escolaridade". Estes apontamentos permitem compreender que a inserção de ferramentas tecnológicas contribui com o avanço da aprendizagem do aluno, e neste caso o uso ou as montagens do LEGO Education produzem este movimento.

Por se tratar de um programa interdisciplinar de robótica, utilizado pelas escolas da Rede SESI no Brasil, pode-se afirmar em diálogo com Oliveira (2013, p.1), que “[...] a robótica educacional pode caminhar se apropriando de conceitos fundamentais da engenharia e da computação, mas principalmente, ela deve se reinventar, inovando e trazendo práticas e usos singulares que dialoguem com a realidade educativa”. Deste modo, compreendemos que; a inserção desta ferramenta permite que os alunos sejam os protagonistas no processo educacional, porque a eles é oportunizada, após a contextualização dos conteúdos pelo educador, a plena liberdade para elaborarem as montagens com a peças LEGO Education, seguindo a dinâmica da aula. Neste processo, caso ocorra alguma dificuldade durante a execução, os alunos são estimulados a perceberem qual passo não foi realizado corretamente para, assim, concluírem com êxito a elaboração da montagem que lhes foi proposta pelo professor.

É oportuno esclarecer que a ZOOM é uma empresa brasileira que representa com exclusividade a LEGO Education no Brasil e desenvolve soluções de aprendizagem inovadoras, que introduzem um novo paradigma na educação: o de que nada supera o modelo do aprender-fazendo, com vistas a promover o desenvolvimento integral de crianças e jovens do século XXI. As atividades desenvolvidas nos fascículos da LEGO Education foram baseadas em propostas e estudos de pesquisadores da área educacional e fundamentadas nos quatro pilares para a educação da Unesco (1998): aprender a fazer, aprender a ser, aprender a conviver e aprender a conhecer (SIGNORELLI, 2016).

Atualmente, conhecimento e educação constituem as grandes exigências do mundo globalizado e, a partir delas, a Unesco (1998) compilou uma lista de características ou competências para este educando do século XXI, quais sejam: comunicação, criatividade, empreendedorismo, flexibilidade, informação, responsabilidade, sociabilização e tecnologia. Diante disso, a propósito da robótica como metodologia de ensino, Oliveira (2013) assinala que, 
Pensar em robótica na educação representa necessariamente pensar na aquisição de uma nova linguagem. No mercado brasileiro há diversos kits de robótica educacional disponíveis, muitos se diferem pela simplicidade - kits mais introdutórios e bem pedagógicos que ainda ensinam pouco sobre a robótica, porém despertam no aluno uma vontade de conhecer mais sobre este universo tecnológico - ou pela complexidade - propiciam uma grande imersão no mundo da robótica, abrindo a possibilidade de se trabalhar, por exemplo, conceitos da física na prática - ao mesmo tempo todos são iguais no que diz respeito a necessidade do aluno conhecer a linguagem própria destes robôs, afinal, um robô sem uma lógica de programação adequada não passa de um objeto decorativo, um monte de pecinhas encaixadas (OLIVEIRA, 2013, p. 2).

Com base nos pilares da Unesco (1998) para a educação e rememorando o aprender fazendo, a robótica tem muito a contribuir para a formação de cientistas, engenheiros, pesquisadores, mas, acima de tudo, para a formação de cidadãos que saibam trabalhar em equipe, que desenvolvam valores e que tenham a consciência de que a ajuda mútua para com o próximo é fundamental em nossa sociedade. No caso do uso das peças LEGO Education, as montagens e soluções promovem experiências enriquecedoras de ensino e aprendizagem, por meio de recursos tecnológicos que envolvem os blocos de montagens, os materiais didáticos curriculares e a formação de professores, pois são estimuladas habilidades e competências dentro de um aprendizado significativo nas salas de aula. A respeito desta forma de pensar a educação tecnológica, Carmo (2013) destaca que,

[...] Tendo em conta que a revolução informática alterou, e continua a alterar, os padrões culturais, é preciso ter consciência de que uma utilização educativa que tire partido das potencialidades que a informática propõe modificará substancialmente a maneira de aprender e de ensinar, os métodos de trabalho e o próprio funcionamento das instituições escolares (CARMO, 2013, p. 35).

As maletas com as peças LEGO Education são desenvolvidas e contextualizadas a partir do material didático e dos fascículos, mas de uma forma interdisciplinar, com o intuito de estimular os alunos a serem investigadores e construírem o conhecimento por meio de suas vivências e atividades práticas. Desta forma, o papel do professor é fundamental ao associar a educação ao uso da tecnologia. Abrantes (2009), em seus estudos sobre a Robótica Educacional, aponta que,

Neste contexto, o professor é o condutor da aprendizagem, é o professor que tem um papel central a criar condições que levem os alunos a aprender, sugerindo projectos, integrando simulações de problemas e situações do dia-adia. No desenvolvimento destes projectos, os alunos a adquirem competências que não só se resumem ao saber, ao saber fazer, ao desenvolvimento da actividade cognitiva mas também ao saber ser, estar e comunicar. Acima de tudo que promovam a criatividade e a inovação (ABRANTES, 2009, p. 46, sic). 
Assim, podemos constatar que o aprendizado é a culminância dessas experiências, desafios e criações em equipe, tendo em vista que os primeiros anos escolares são a base que prepara a criança para a vida, o que aponta para a necessidade de fazê-la reconhecer a importância da convivência e do trabalho em conjunto com os demais colegas. Os materiais da LEGO Education estimulam e desenvolvem habilidades sociais e emocionais de maneira envolvente, prática, criativa e lúdica, assim o porquê de pontuarmos a importância do uso desta ferramenta tecnológica nos Anos Iniciais do Ensino Fundamental.

A Robótica Educacional é uma das possibilidades de aplicação pedagógica das tecnologias digitais em uso crescente no processo de ensino-aprendizagem nos Anos Iniciais e, por meio dela, é possível perceber a evolução sistematizada dos alunos. Silva (2013, p. 9) destaca que "Vivemos em tempos de ressignificações, de profundas mudanças, de contestações de toda ordem, de crise da ciência e da sociedade moderna". Por isso, no caso do material LEGO Education podemos dizer que ele promove todo este diferencial no ensino-aprendizagem nas crianças que dele fazem o uso, trazendo um novo significado neste processo.

No caso do Brasil, as escolas da rede SESI de Educação, inserem a Robótica Educacional em suas atividades curriculares, ao desenvolver projetos de pesquisa e ao participar também da Olimpíada Brasileira de Robótica (OBR), que é uma iniciativa pública, gratuita e sem fins lucrativos, totalmente dedicada às escolas, professores e jovens brasileiros que tem por objetivo despertar o interesse pela ciência e tecnologia, utilizando a temática da robótica como ferramenta para aprender e também encontrar soluções que possam melhorar o dia a dia das pessoas (ZOOM, 2020).

Existem razões práticas para a inserção da metodologia LEGO Education na rotina das aulas, entre elas, podemos destacar, de um lado, o fato dela se constituir em um facilitador na compreensão dos conteúdos curriculares, e de outro, o de desenvolver habilidades essenciais para o futuro dos alunos. No entanto, vale a pena se atentar aos dizeres de Cortella (2014), em torno dessas questões. O referido autor ressalta que,

Não é a tecnologia que torna uma mente moderna. Mas uma mente moderna não recusa tecnologia quando ela é necessária - e ela o é em inúmeros momentos e não o é em tantos outros", assim nos dizeres do autor acerca do uso das tecnologias, percebemos entre muitos benefícios que o uso das TICs, com especificidade a Robótica Educacional promove o ensino-aprendizagem, pois, estimula o espírito investigativo do aluno de forma que encontre desafios e as devidas soluções para os mesmos, sem contar que enaltece o trabalho em equipe, o planejamento, a cooperação, o diálogo, a pesquisa e a tomada de decisões, pois [...] em maior ou menor escala, a tecnologia invadiu a sala de aula (CORTELLA, 2014, p.59). 
De modo geral, o que torna a robótica relevante no aprendizado interdisciplinar, é o conceito STEAM - sigla em inglês para Ciências, Tecnologia, Engenharia, Artes e Matemática - uma metodologia integrada e baseada em projetos; pautados e desenvolvidos a partir de assuntos da vida real e situações do cotidiano, o que estimula o uso da criatividade para resolver diferentes questões no dia a dia (ZOOM, 2020).

Sendo o aluno parte fundamental nesse processo de ensino e aprendizagem, como protagonista no desenvolvimento e tomada de decisões, norteando os seus estudos aos conteúdos didáticos, mas também nas aulas práticas nos laboratórios de robótica para executar as montagens com o material da LEGO Education. Assim, diante dos discursos pedagógicos sobre o uso das tecnologias digitais, para melhorar a proficiência nos componentes curriculares, podemos apontar que a inserção da ferramenta LEGO Education nas atividades escolares promove um diferencial no ensino-aprendizagem dos alunos que o fazem habitualmente, dado este que se torna perceptível no desenvolvimento das atividades propostas pelos professores aos alunos que usam esta tecnologia, conforme explicitamos a seguir.

\section{O PROFESSOR E O USO DAS TECNOLOGIAS EM SALA DE AULA: A EXPERIÊNCIA COM A FERRAMENTA LEGO EDUCATION NA ESCOLA SESI DOURADOS}

No cenário educacional globalizado, que é permeado pelas tecnologias, o desafio dos professores é introduzir as TICs ao processo de ensino-aprendizagem dos alunos. Por que um desafio? Porque, muitas vezes, a escola abarca ferramentas tecnológicas, porém, alguns professores não as compreendem como ferramentas pedagógicas na prática educacional com os alunos. Mesmo essas ferramentas estando presentes no cotidiano de instituições escolares, como as escolas da Rede SESI de Educação no Brasil e, principalmente, nas esferas externas às escolas, alguns professores, por determinadas circunstâncias, não se sentem habilitados ou mesmo aptos para inseri-las em suas atividades, especialmente com grau avaliativo de ensino-aprendizagem.

Nessas circunstâncias, a educação no século XXI se constitui de forma dinâmica e exige novas competências e abordagens por parte dos profissionais da educação, portanto, para que possamos compreendê-las e aplicá-las, é importante, rever o papel do professor na sala de aula. Ao educador, é designado a mediação do aprendizado dentro do ambiente educativo, utilizando seu conhecimento e amparo nas ferramentas tecnológicas para potencializar as habilidades nos seus alunos, ajudando-os na superação de desafios no processo de ensino-aprendizagem. O desafio dos profissionais da educação é o de se manterem atualizados acerca das novas metodologias de ensino e desenvolverem práticas pedagógicas eficientes, pois elas fortalecem e enriquecem seu aprendizado no exercício da função docente. Nesse entendimento, Weisz (2018) ressalta que, 
[...] Vivemos um momento de revisão da educação escolar, de seu papel e seu alcance. Juntamente com isso, vem o desafio da construção de um perfil profissional para o professor com base no seu trabalho em sala de aula, mas que se amplia para o desenvolvimento do projeto educativo da escola (WEISZ, 2018, p.7).

Assim, no contexto atual, os professores apresentam as informações, os conteúdos e apontam aos alunos o caminho de como lidar com elas, de como resolver problemas. Desta maneira, os educadores são apontados como facilitadores do processo de aprendizado, na mediação e na articulação do que está sendo lecionado durante as aulas, exigindo assim, por parte do professor flexibilidade e um olhar atento para alcançar os objetivos propostos na aprendizagem do educando.

Com o avanço das tecnologias é complicado não as adaptá-las ao contexto educacional para a construção do conhecimento e do aprendizado do educando. Fazer a adequação das ferramentas tecnológicas é muito salutar para conseguirmos êxito neste processo, pois o uso das plataformas digitais de ensino, auxilia professores e alunos a aproveitarem o melhor que o mundo globalizado e tecnológico oferece. Embora nem sempre seja possível, aos professores terem o acesso às ferramentas tecnológicas, dependendo da instituição escolar em que se trabalha. Na Escola SESI, essa tarefa é facilitada devido ao grande investimento por parte da unidade de ensino, em tecnologias e formações para os profissionais da educação que nela atuam.

A Escola do SESI Dourados é considerada a maior unidade escolar do Mato Grosso do Sul em números de alunos e uma das pioneiras no estado em desenvolvimento de novas tecnologias. Nela, o uso da Robótica Educacional foi implantado e iniciado no ano de 2013, com a inserção da ferramenta LEGO Education, sendo implementado desde os Anos Iniciais e Finais do Ensino Fundamental, e também no Ensino Médio. Além das atividades cotidianas desenvolvidas no Laboratório Tecnológico de Robótica, a escola promove Torneios Interclasses, para que os alunos participem e apresentem seus projetos de pesquisa e Oficinas de Robótica nas Universidades de Dourados e região (REGIMENTO ESCOLAR, 2020).

Devido ao excelente desempenho na utilização da Lego Education desde os Anos Iniciais, a Escola do SESI Dourados já conquistou vários prêmios regionais e nacionais com as equipes dos seus alunos matriculados nos Anos Finais do Ensino Fundamental e Ensino Médio, os quais ingressaram na instituição desde a implementação desta ferramenta. Isto demonstra que trabalhar com os conteúdos didáticos aliados às atividades interdisciplinares como a robótica promove um diferencial na aprendizagem dos alunos, além de inseri-los no mundo das ciências e da tecnologia com desenvoltura e trabalho em equipe (REGIMENTO ESCOLAR, 2020). 
Neste contexto, desenvolver atividades com a ferramenta LEGO Education, permite que a educação esteja alinhada a valores como ética e o respeito, pois essas são algumas premissas no uso da Robótica Educacional. Libâneo (1998, p. 45) argumenta que "[...] a formação de atitudes e valores, perpassando as atividades de ensino, adquire, portanto, um peso substantivo na educação escolar, porque se a escola silencia valores, abre espaço para os valores dominantes no âmbito social" e que, nem sempre trazem benefícios para a educação. Na referida escola, os professores desenvolvem as atividades com o material LEGO Education de acordo com o conteúdo que esta sendo lecionado, procurando contextualizá-lo de uma forma mais próxima da realidade da criança que, por meio de um ambiente de aprendizagem e interação, e através das montagens, objetiva $o$ desenvolvimento do aluno tanto em relação ao raciocínio lógico quanto às, diferentes habilidades e competências.

Podemos desta forma citar exemplos práticos de como ao lecionar os conteúdos curriculares na disciplina de Matemática relacionados a "pesos e medidas" associá-los a elaboração da montagem de uma "balança de dois pratos" com as peças da LEGO Education, onde os alunos podem compreender como os alimentos são pesados nos supermercados. Também, abordando temas nos conteúdos de História acerca dos "meios de transporte" atuais ou antigos, é possível desenvolver a montagem de um "carro com movimento sincronizado" e promover durante esse processo que permeia as montagens reconhecer a importância dos transportes para o deslocamento diário das pessoas. Estas são algumas das inúmeras formas que são desenvolvidas as atividades com os alunos, a partir da contextualização dos conteúdos do material didático e depois inseridos na prática através das montagens desenvolvidas no Laboratório Tecnológico de Robótica da escola.

Observamos que durante o processo inicial de planejar as aulas e até chegar a culminância com a elaboração das montagens, todo o caminho percorrido para os direcionamentos e execuções passam pela contextualização dos conteúdos didáticos associados aos fascículos da LEGO Education, seguindo as matrizes curriculares da escola (REGIMENTO ESCOLAR, 2020). Deste modo, os professores, além de transmissores de informações, precisam reconhecer no aluno essas formas de aprendizado e perceber $o$ seu envolvimento e a realidade educacional e social que o cercam. Esta ação norteará as suas práticas pedagógicas para saber o que ensinar, e como ensinar, trazendo significado a aprendizagem do educando, ao passo que, o conhecimento prévio do aluno deve ser respeitado e ampliado durante as aulas. Neste entendimento, Libâneo (1994, p. 88) aponta que "o trabalho docente é a atividade que dá unidade ao binômio ensino-aprendizagem, pelo processo de transmissão-assimilação ativa de conhecimentos, realizando a tarefa de mediação na relação cognitiva entre o aluno e as matérias de estudo".

É interessante pontuar o quanto os alunos nos Anos Iniciais aprendem durante as aulas tecnológicas com o uso da ferramenta LEGO Education, pois o trabalho em equipe e a autonomia que eles desenvolvem perante os desafios na elaboração das montagens são percebidos pelos professores que os acompanham nestas atividades. Desta forma, 
podemos ainda exemplificar que, ao relacionar a montagem do "planetário" torna-se mais fácil para o sujeito, a aprendizagem e a compreensão do componente curricular de Ciências da Natureza acerca do "sistema solar" e dos movimentos de rotação e de translação da Lua e da Terra, ou ainda com a elaboração das montagens da "esteira rolante" e do "elevador" associadas as questões da acessibilidade na locomoção das pessoas com necessidades especiais.

Sendo assim, o norte principal dos educadores que utilizam a robótica como recurso tecnológico são oferecer oportunidades para os alunos se engajarem em atividades de exploração, pois, ao manipularem as peças LEGO Education, eles constroem o conhecimento baseados em situações do dia a dia. Tardif $(2002$, p. 70$)$ ressalta que "o educador não trabalha sobre os alunos, mas com e para os alunos" e, assim, precisa estar atento ao ensino-aprendizagem da criança. Essas inferências nos levam à compreensão que o educando valida as suas experiências educacionais norteadas no acompanhamento e monitoria do professor, pois, juntos, professores e alunos constroem uma aprendizagem significativa.

Deste modo, o educador deve assumir sua responsabilidade perante a dinâmica escolar através do uso das tecnologias, e também reconhecer os saberes dos alunos. Essa relação deve ser estabelecida a partir da legitimidade desses papéis, construídos a partir do diálogo entre os pares envolvidos, pois precisa permear o respeito mútuo entre docente e discente. Tais ações colaborativas são fundamentais para a construção do processo de ensino-aprendizagem demonstrado por meio da inserção da ferramenta LEGO Education.

\section{CONSIDERAÇÕES FINAIS}

Um artigo desta natureza nos permite compreender o papel desenvolvido pela Robótica Educacional com a inserção da ferramenta LEGO Education nas Escolas da Rede SESI no Brasil, com especificidade aqui pontuado neste artigo pelo trabalho desenvolvido na Escola SESI da cidade de Dourados-MS. Nesse sentido, podemos evidenciar que o uso sistematizado do material permite que sejam desenvolvidas diversas competências e habilidades nos alunos dos Anos Inciais do Ensino Fundamental.

Ainda foi possível observar que a partir da implementação e utilização das maletas LEGO Education introduzidas na Escola Sesi Dourados, no ano de 2013, promoveu-se um diferencial no desenvolvimento e no ensino-aprendizagem dos alunos, levando-os à construção e ao aprimoramento dos saberes tecnológicos de forma evolutiva, prática e colaborativa, com interdependência, criatividade e aptidão para com a resolução de problemas. 
Concluímos que os discursos pedagógicos acerca das abordagens tecnológicas na educação, perfazem um caminho centrado na performance do educando, haja vista, que as tecnologias digitais são imprescindíveis no atual cenário educacional, pois fazem parte do contexto cultural dos alunos, cuja geração tem sido a mais influenciada com o avanço tecnológico. Neste sentido, cabe aos educadores mediarem o aprendizado por meio do uso da Robótica Educacional.

Por fim, apontamos que a relevância deste estudo para a área da Educação deve-se, à escassez de pesquisas na área educacional que versam sobre o uso da ferramenta LEGO Education nos Anos Iniciais do Ensino Fundamental. Esperamos que este artigo possa contribuir com as pesquisas acerca dos discursos pedagógicos e o uso das tecnologias digitais na educação.

\section{REFERÊNCIAS}

ABRANTES, Paula Cristina Rolo. Aprender com Robots. Universidade de Lisboa. Faculdade de Ciências. Departamento de Educação. Mestrado em Educação. Especialização: Tic e Educação. Dissertação. 160f. 2009.

Disponível em: https://repositorio.ul.pt/bitstream/10451/3646/1/ulfc055872_tm_Paula_Abrantes.pdf. Acesso em: 20 jul. 2020.

CARMO, Bruna Santos. A robótica educativa no desenvolvimento do raciocínio matemático. Universidade do Algarve. Escola Superior de Educação e Comunicação. Relatório da Prática de Ensino Supervisionada. Mestrado em Ensino do $1 .^{\circ}$ e $2 .^{\circ}$ Ciclos do Ensino Básico. 76f. 2013. Disponível em:

https://sapientia.ualg.pt/bitstream/10400.1/3625/1/A\%20Rob\%C3\%B3tica\%20Educativ a\%20no\%20Desenvolvimento\%20do\%20Racioc\%C3\%ADnio\%20Mate.pdf. Acesso em: 12 ago. 2020.

CORTELLA, Mario Sergio. Educação, escola e docência: novos tempos, novas atitudes. São Paulo: Cortez, 126f. 2014.

DELORS, Jacques. Educação: um tesouro a descobrir. Relatório para a UNESCO da Comissão Internacional sobre Educação para o século XXI. São Paulo: Cortez, 1998. Disponível em:

http://dhnet.org.br/dados/relatorios/a_pdf/r_unesco_educ_tesouro_descobrir.pdf. Acesso em: 27 jul. 2020.

MIZUKAMI, Maria da Graça Nicoletti. Ensino: as abordagens do processo. São Paulo: EPU, 119f. $1986 . \quad$ Disponível em: 
https://interdisciplinarmackenzie.files.wordpress.com/2015/02/livro-ensino-asabordagens-do-processo-mizukami.pdf. Acesso em: 8 ago. 2020.

OLIVEIRA, Felipe Silva de. Alfabetização e Robótica: Uma Abordagem Inédita da Robótica na Formação de Professores. Mostra Nacional de Robótica. 2013.

Disponível em: http://sistemaolimpo.org/midias/uploads/103d2234d951ccb021062a8a5599b1bf.pdf. Acesso em: 19 ago. 2020.

PIAGET, Jean. O nascimento da inteligência na criança. Rio de Janeiro, Zahar, 1974. Disponível em: http://www.dominiopublico.gov.br/download/texto/me4676.pdf. Acesso em: 13 jul. 2020.

SESI. Serviço Social da Indústria. Rede SESI/MS de Educação. Sesi discute novas parcerias de educação com a Zoom Education. 2015. Disponível em:

http://www.fiems.com.br/noticias/sesi-discute-novas-parcerias-de-educacao-com-azoom-education/18939. Acesso em: 01 ago. 2020.

Rede SESI/MS de Educação. Regimento Escolar 2020. Disponível em: https://www.sesims.com.br. Acesso em: 16 ago. 2020.

SIGNORELLI. Vinícius. Programa Educação Tecnológica INVENTUS: anos iniciais. $1^{a}$ Ed.São Caetano do Sul, São Paulo. Agnus Educação e Tecnologia, 2016. Disponível em:

https://www.sesieducacao.com.br/conecta/pdf/e65ba76286c60329b58667bbe8be94cc.p df. Acesso em: 11 ago. 2020.

SILVA, Janssen Felipe da. HOFFMANN, Jussara. ESTEBAN, Maria Teresa. (Org.) Práticas avaliativas e aprendizagens significativas: em diferentes áreas do currículo.10a Ed. - Porto Alegre: Mediação, 128f. 2013.

TARDIF, Maurice. Saberes Docentes e a formação profissional. $2^{\mathrm{a}}$ Ed. Petrópolis: Vozes, 111f. 2002. Disponível em: https://edisciplinas.usp.br/pluginfile.php/2724102/mod_resource/content/1/Saberes\%20 docentes $\% 20 \mathrm{e} \% 20$ forma\%C3\%A7\%C3\%A3o\%20profissional.pdf. Acesso em: 22 jul. 2020.

VYGOSKI, Lev Semyonovich. A formação social da mente. São Paulo: Martins Fontes, 1998. Disponível em:

https://edisciplinas.usp.br/pluginfile.php/3317710/mod_resource/content $/ 2 / A \% 20$ forma cao\%20social\%20da\%20men. Acesso em: 26 jul. 2020. 
WEISZ, Telma. O diálogo entre o ensino e a aprendizagem. $3^{\text {a }}$ Ed. São Paulo: Ática, 135f. 2018.

ZOOM, Education for life. Uma revolução na sala de aula. 2020. Disponível em: https://zoom.education/. Acesso em: 14 ago. 2020.

\footnotetext{
i Material de Robótica Educacional (LEGOEduaction). Disponível em: https://www.infoescola.com/curiosidades/lego/. Acesso em: 10 ago. 2020.
}

*Graduada em Pedagogia pela Faculdade Integrada de Fátima do Sul (FIFASUL) com integração de créditos pela Universidade Federal de Mato Grosso do Sul (UFMS), Especialista em Educação pela Universidade Federal da Grande Dourados (UFGD), Mestra em Educação pela Universidade Federal da Grande Dourados (UFGD), Professora na Educação Básica (REDE SESI/MS), Professora no Curso de PósGraduação EAD do Centro Universitário da Grande Dourados (UNIGRAN). E-mail: marizabackes@hotmail.com.

**Graduada em História (Licenciatura e Bacharelado) pela Faculdade de História, Direito e Serviço Social (UNESP), Mestra em História pela Faculdade de História, Direito e Serviço Social (UNESP), Doutora em Educação pela Faculdade de Educação da Universidade de São Paulo (USP), Pós-Doutorado em Educação pela Faculdade de Educação da Universidade de São Paulo (USP), Professora Associada II da Faculdade de Educação da Universidade Federal da Grande Dourados (UFGD) na Graduação e na Pós-Graduação em Educação (Mestrado e Doutorado). Editora da Revista Educação e Fronteiras. Líder do GEPHEMES. Email: AlessandraFurtado@ufgd.edu.br. 